\title{
Editorial
}

\section{Think like a Rolls Royce, act like Beanie Babies}

At the time of writing this editorial there are three big brand stories hitting our front and back pages: Nike, Rolls Royce and Beanie Babies. Yes. Beanie Babies! If you haven't heard of them yet then you are obviously living in a dinky child-free heaven and for your information Beanie Babies are a range of small stuffed animal toys that are the latest collectible craze in the USA and now here. Retailing at $\mathcal{E}^{3.95}$, the scarcer ones are being auctioned on the Internet for thousands of dollars.

So I thought it might be interesting to consider what these three brand headliners have to teach us about brands and brand management in the late 20th century - a kind of bottom up approach to studying brands. (God, after all, is in the detail!)

So what are the lessons?

The first and most obvious lesson is that brands are news - both consumer and financial news!

Indeed, it is currently hard to read a magazine or paper without bouncing into some discussion of whether VW paid too much, or too little, whether Nike is just down or actually down and out, and just why Beanie Babies?

In short we have got what we asked for. It would be near impossible now to find a CEO or finance director who doesn't recognise the potential importance and value of brands to a business.

The need to put the value of acquired brands on to the balance sheet will just confirm what has been in the last 10 years or so a veritable sea-change in how business perceives the product of what we do.
As a result, of course, there will be a seachange, as yet hardly felt I would believe, in these communities' relationship with those people who manage their valuable assets and, of course, how we do it.

At first glance it would seem we have a lot to gain (greater respect, better career opportunities etc). But there is a sting in the tail we will become more and more accountable. We can expect more brand measures, greater demands for us to 'speak financial'.

This is a whole new skill-set that we will have to come to grips with and incorporate.

But it is not just in the financial pages that brands are stories. Each of the brands Nike, Rolls Royce, Beanie Babies - are firmly in the general public domain.

It was Jeremy Bullmore, I believe, who pointed out that part of the very core essence of what is a brand is its shared understanding, its 'public' perception.

'Brands have in common a kind of fame ... fame lends a certain value to things and to people. Famous things can be shared, referred to, laughed about. Famous things are literally a talking point.'

$$
\text { Jeremy Bullmore }
$$

It has taken the tabloid press a little longer to spot this fact, but as journalists run out of new famous things (done politicians, done film stars, done supermodels, done sport, done the Royal Family, done Anthea Turner!) they are turning their attention to brands and so, like a Tory MP in bed with his assistant, or Stan Collymore on a bad 
night, we come under the intense scrutiny of the world of the tabloids and the exposé.

Again, I would argue this process is only at the beginning. We are now linked for better or for worse. Better, because brands have already discovered how this oxygen of publicity can breathe extra life into sales (Häagen Dazs, Wonderbra and FCUK). Worse, because tabloidesque examination can peel back brand layers to an uncomfortable degree and leave brand values naked, (as 'Nike exploit third world workers' type headlines testify, and the Beanie Babies will undoubtedly earn itself the 'starving parents forced to sell internal organs to buy special Beanie' headline).

Such public ownership creates debates about the process behind the benefit about the core motives. This again creates new demands on brand management, new concepts of the range and depth of consideration and analysis we need to do to be on top of the brand equity.

For example, for me, one of the most damaging parts of the Rolls Royce story is the publicising of the fact that the workforce stays with VW - in other words the Roller you get in the future will no longer be made with the same craft skills that old Rollers were made with. I wonder whether BMW managers have even begun to think about that as a brand issue rather than a business issue?

Again, the simple conclusion is brand managers will have to learn new skill-sets in this case media management.

So one thing we can be sure of is things are going to get busier.

But, if these are just some of the lessons simply from the fact that these brands are stories, what are the lessons from the content of the stories? What does the purchase of Rolls, the decline of Nike and the rise of Beanie Babies tell us about brands and their management?

On the face of it, they could not be more different brands - they appeal to different ages (the child, youth, the mature and successful). They work across different price brackets (the cheap, the premium and the luxury). They embrace different values fun, style, quality and so on and so on.

However, if the brand owners sat down together in a kind of "which brand owner would you like a One2One with?' session I believe they would actually have interesting things to learn from each other.

Beanie Babies is actually a great lesson in how constantly to stimulate the most fickle and faddish consumer - the child. They issue new designs, and withdraw favourites, and so create constant conversation and interest; on the web, in newsletters and around the play area. The brand embraces change.

In today's accelerated culture, where the brand management is faced with a constant challenge of how to re-engage and revitalise the brand's relationship with its consumer in the face of intense competition, Beanie Babies is worth studying no matter what age your brand's consumer.

Accelerated Culture has spawned a different type of consumer, a consumer who is in control, who is media literate and has marketing savvy; but also a consumer who has too many choices to make and not enough time to make them in. Successful consumers, in the late 1990s, have developed a necessary talent for speed editing: filtering out the data that doesn't need to be absorbed, the decisions that don't need to be made.

As a result, consumers have a voracious appetite for information, ideas and stimulus. They have a tremendous capacity to edit, digest, adopt and dispose, and then move on. Consider how quickly new preferences and passions have become old news, redundant choices across the full gamut of cultural life - from Take That to Spice Girls to All Saints; from black to brown to grey; from Thailand to Vietnam to Morocco.

The type of behaviour we used to associate almost exclusively with pop music and 
fashion has now become the norm in all aspects of life. Consumers treat brands like bands. Beanie Babies understand this. Indeed they play to it and revel in it.

Strangely, I would encourage Rolls Royce to take note of Beanie Babies' success. As a brand with a glorious past, but the feel of living not just off the past but in the past, Rolls Royce could learn from Beanie Babies how to live more fully in the absolute present, indeed in the news, for this is the challenge that faces BMW in managing the Rolls Royce equity - how to contemporise it and how to make it relevant for today's modern consumer.

On the other hand, Beanie Babies would love to learn the lesson of how to build an enduring relationship, of how to become a classic rather than a fad.

For in the same world of change described earlier consumers also look to brands of longevity, integrity and authenticity. In other words, brands they can trust as symbols (almost pseudo-religious) of consistency in the flux of modern living. If Beanie Babies is to go the way of Barbie rather than the Cabbage Patch Doll it needs to learn about these values from Rolls, which is, after all, a peerless example of such consistency and certainty.

And Nike? What can Nike learn?
I believe Nike could actually learn from both brands in thinking how to manage the tension between these two apparently contrary poles of consumer need - consistency and inconsistency. On the one hand, Nike has lost its contemporary currency, its fashion, for want of a better word, status. On the other hand, it has not, one would argue, built sufficient long-term values to withstand this withdrawal of 'coolness'. It has not built the levels of belief and trust of a classic. Its future, over the next five years, is in managing both these aspects.

As such, Nike represents maybe the key dilemma of many brands in today's accelerated culture: how to manage consistency inconsistently, how to develop a long-term set of values which can be owned and consumers can rely on whilst making sure those relationships stay fresh and current.

So, in among learning how to speak financial, and how to become a brand spindoctor, the brand manager faces one final pressure 'how to think Rolls Royce and act Beanie Baby?'

One final thing these brand stories tell us then is very clear - the job is going to get more challenging not less!

Nick Kendall Editorial Board 